Polona Dakič

Podiplomska študentka,

Univerza na Primorskem,

Fakulteta za management

polona.dakic@gmail.com

\title{
Celostna nakupna izkušnja na prepihu sprememb
}

Nakupovanje živil in potrošnih dobrin je danes za večino ljudi nekaj samoumevnega - je del naše kulture. Lahko bi celo rekli, da gre za moderno obliko lova in nabiranja. Tako kot so v pradavnini moški hodili na lov, ženske pa nabirale zelišča in ostale rastline, da so zagotovili preživetje svojih družin, danes to potrebo uresničujemo preko nakupovanja. Skozi tisočletja se je potreba po nakupovanju izrazito spreminjala. Celostna nakupna izkušnja postaja vedno kompleksnejša zaradi vedno širše ponudbe trgovcev, njihovega širjenja po različnih državah, digitalizacije in tehnologije. Trgovci so postali bolj razvejani, premik se je zgodil tudi na strani proizvajalcev, saj so digitalni procesi in razmah tehnologije pripomogli $\mathrm{k}$ pospešenemu inoviranju njihovih izdelkov ter storitev. Tako kot pri trgovcih se je tudi pri njih pojavila možnost širjenja poslovanja po vsem svetu. Posledično imajo potrošniki na voljo vedno več izbire različnih izdelkov, storitev in blagovnih znamk, kar vodi do sprejemanja večjega števila odločitev, kar pa ni nujno, da zagotavlja tudi večje zadovoljstvo.

Ključne besede: celostna nakupna izkušnja, vedenje potrošnikov, digitalizacija, tehnologija

\section{A Holistic Shopping Experience on the Brink of Change}

Shopping for food and other goods is today for most people something normal - it is part of our culture. We could even say that it is a modern form of hunting and gathering. Just as in ancient times men went hunting and women gathered herbs and other plants to provide basic goods for the survival of their families, today we are realizing this need through shopping. Over the centuries, the need to shop has changed remarkably. Customer journey is becoming more complex due to the increasing supply of retailers and their rapid spreading across different countries. Retailers have became more diversified, the shift also happened on the manufacturers' side. The boom in digitalization and technology have helped accelerate the innovation of their products and services. Like retailers, they too have been given the opportunity to expand their business around the world. In addition, consumers have more and more choices of different products, services and brands, which in turn leads to more decisions, but this does not necessarily provide greater customer satisfaction.

Keywords: customer journey, customer behavior, digitalization, technology

(cc)BY-SA https://doi.org/10.26493/1854-4231.16.25-30

Vedenje potrošnikov $\mathrm{v}$ prodajnem okolju predstavlja področje raziskovanja že več kot 70 let (npr. Applebaum 1951). Nakupovanje že dolgo ni zgolj proces, s pomočjo katerega potrošnik pride do želenega izdelka ali storitve, postalo je veliko več postalo je družbena izkušnja (Rompay idr. 2012). Današnji potrošniki od proizvajalcev in trgovcev pričakujejo interaktivno in holistično naku- pno izkušnjo, ki jih zabava, stimulira, ima nanje emocionalni vpliv ter spodbuja njihovo kreativnost (Foster in McLelland 2015). Te okoliščine omogočajo kreiranje zapomljivih potrošniških izkušenj znotraj prodajnega okolja. Predstavljajo priložnost, da proizvajalci in trgovci svoje marketinško-prodajne aktivnosti ustvarijo na način, ki bo drugačen od njihove konkurence. Raz- 
lični avtorji so raziskovali, kako proizvajalci in trgovci kreirajo nakupne izkušnje za potrošnika. Želeli so poiskati način, s katerim bi ugotovili, kaj in kako potrošniki zaznavajo, čutijo, kako razmišljajo, reagirajo in na kakšen način se povezujejo $\mathrm{z}$ blagovnimi znamkami. Spremembe in nadgradnje socialnega ter poslovnega okolja so $\mathrm{v}$ zadnjih desetletjih povzročile precejšnje modifikacije $\mathrm{v}$ potrošniškem vedenju. Ostale pomembne stvari, ki so vplivale na potrošnike, so tudi zmanjševanje vpliva tradicionalnih medijev in zvestobe blagovnim znamkam ter nastanek vedno učinkovitejših načinov, kako priti v interakcijo s potrošniki na mestu nakupa (angl. POP - point of purchase) (Stahlberg in Maila 2012). Potrošniki imajo danes na voljo vedno več izbire različnih izdelkov, storitev in blagovnih znamk, kar lahko pripelje do prevelike količine odločitev (angl. choice overload, paradox of choice). To pomeni, da veliko izbire namesto osrečevanja vodi do stresnih situacij, lahko pa tudi zakomplicira proces odločanja. O tem pojavu je pisal že francoski filozof Jean Buridan (1300-1358) v 14. stoletju, mnogo kasneje pa so to področje raziskovali tudi ostali (npr. Lipowski 1970). Da soočanje potrošnikov s preveč privlačnimi možnostmi zmanjša njihovo motivacijo, da bi sploh karkoli izbrali, potrjujejo tudi aktualnejše raziskave, narejene v zadnjih dvajsetih letih (npr. Reutskaja in Hogarth 2009). Schwartz (2004) izpostavlja, da se potrošniki v situacijah, ko imajo veliko izbire in jim to omogoča boljšo odločitev, počutijo slabše. To pa zato, ker se njihova pričakovanja glede vseh dobrih in dostopnih možnosti povečajo. Takrat, ko morajo potrošniki upoštevati veliko alternativ, si predstavljajo privlačne lastnosti vseh tistih alternativ, ki so jih zavrnili in se zaradi tega počutijo manj zadovoljne $\mathrm{z}$ izbrano alternativo. $\mathrm{Na}$ potrošnika vplivajo tako funkcionalne kot tudi hedonistične vrednote, zato pri odločanju iščejo različna razmerja med njimi (Babin, Darden in Griffin 1994). V skladu s temi vrednotami so odločitve potrošnika lahko racionalne (kognitivne) ali emocionalne (afektivne) (Shankar 2011).

Covid-19, z njim povezana karantena in vse ostale omejitve, ki so jih bili potrošniki deležni v zadnjem letu, so hitro in korenito spremenili potrošniško nakupno vedenje (»The Evolving Consumer: How COVID-19 Is Changing the Way We Shop« b.1.). Že prve spremembe, ki so se začele dogajati na strani trgovcev in so bile predvsem povezane $\mathrm{z}$ varnostjo, so vplivale na potrošniške navade. Trgovci so začeli krajšati svoj delovni čas, da so lahko počistili in ponovno napolnili police $\mathrm{z}$ izdelki. Začeli so meriti temperaturo ob vhodih $\mathrm{v}$ prodajalne, obvezna sta postala uporaba rokavic in mask $\mathrm{v}$ zaprtih prostorih ter razkuževanje rok, prav tako pa smo bili priča dolgim vrstam pred prodajalnami pretežno z živili, saj je bilo število oseb na določeno kvadraturo omejeno. Vse to je vplivalo na vedenje potrošnikov in modifikacijo njihove celostne nakupne izkušnje, saj so se morali hitro prilagoditi novi situaciji, ki je zahtevala veliko improvizacije. Kljub vsem spremembam pa raziskave kažejo, da naj bi se potrošniki po koncu covida-19 začeli vračati $\mathrm{k}$ starim navadam, vendar pa obstaja verjetnost, da bodo te nekoliko preoblikovane, predvsem zaradi tehnološkega napredka in zaradi bledenja meje med službo, prostim časom in učenjem od doma (Sheth 2020). To se odraža predvsem $v$ tem, da so se potrošniki na vseh področjih začeli intenzivneje srečevati z digitalnim svetom. Nakupovanje oz. naročanje preko spleta, dostava na dom in prevzemi naročenega blaga v prodajalnah so postali del potrošniškega vsakdana. Zaradi novosti, negotovosti in različnih stisk, s katerimi so se srečevali potrošniki, jih je nakupovanje veliko dojemalo kot stres, kar je imelo za posledico manj pogosto obiskovanje fizičnih prodajaln. Tisti, ki so prej kupovali večkrat tedensko, so v času covida-19 zmanjšali svoje nakupe in v povprečju nakupovali enkrat na vsaka dva tedna. Pričakovanja potrošnikov so se zvišala, saj od trgovcev pričakujejo, da se v času izrednih razmer prilagodijo situaciji ter jim ponudijo hiter in varen nakup ne glede na to, ali kupujejo preko spleta ali v fizični prodajalni (Briedis idr. 2020).

Kakor povzemata Bagdarejeva in Jain (2013) lahko potrošniško izkušnjo $\mathrm{v}$ prodajnem okolju definiramo kot vsoto vseh kognitivnih, emocionalnih, senzoričnih in vedenjskih odzivov, ki nastanejo med celotnim procesom nakupovanja, kar vključuje tudi interakcijo $\mathrm{z}$ ljudmi, objekti in $\mathrm{s}$ procesi znotraj prodajnega okolja. Na tem mestu bomo obrazložili tudi koncept celostne nakupne izkušnje (angl. customer journey - CM). Lemonova in Verhoef (2016) pravita da gre za seštevek vseh nakupnih izkušenj, ki jih potrošnik doživi v procesu nakupovanja. Le-te so sestavni deli treh različnih faz, ki skupaj tvorijo celostno nakupno izkušnjo. Gre za prednakupno fazo (angl. prepurchase phase), fazo nakupa (angl. purchase phase) in ponakupno fazo (angl. postpurchase phase). Vse izkušnje znotraj posameznih faz so interaktivne ter dinamične. $\mathrm{V}$ prednakupni fazi se poslužujemo marketinga blagovnih znamk (angl. brand marketing), v fazi nakupa prodajnega marketinga (angl. trade marketing), $\mathrm{v}$ ponakupni fazi pa poprodajnega marketinga (angl. after sale marketing). Obi- 
Preglednica 1 Opis 3-stopenjskega miselnega marketinškega modela (Ertemel in Başc1 2015)

\begin{tabular}{ll}
\hline Koraki & Opis korakov \\
\hline $\begin{array}{l}\text { 1. korak: dražljaj } \\
\text { (angl. stimulus) }\end{array}$ & $\begin{array}{l}\text { Spodbujanje potrošnika o razmisleku o izdelku ali storitvi (npr. oglas na TV, oglas } \\
\text { v časopisu ali v reviji, spletno oglaševanje, brskanje po spletu, spletna primerjava } \\
\text { izdelkov, branje spletnih mnenj). }\end{array}$ \\
\hline $\begin{array}{l}\text { 2. korak: prvi trenutek resnice } \\
\text { (angl. first moment of truth) }\end{array}$ & $\begin{array}{l}\text { Izkušnja potrošnika z izdelkom v prodajnem okolju (npr. dogajanje znotraj pro- } \\
\text { dajnega okolja, pri polici - ogledovanje izdelka in njegove embalaže, branje bro- } \\
\text { šure o izdelku ali storitvi, pogovarjanje s prodajalcem, ogledovanje oznamčenih } \\
\text { materialov (angl. point of sale materials - POSM), preizkušanje vzorcev). }\end{array}$ \\
\hline $\begin{array}{l}\text { 4. korak: drugi trenutek resnice } \\
\text { (angl. second moment of truth) }\end{array}$ & $\begin{array}{l}\text { Izkušnja potrošnika z izdelkom po nakupu. V tem koraku je ključno vprašanje: Ali } \\
\text { je izdelek dosegel pričakovanja potrošnika? }\end{array}$ \\
\hline
\end{tabular}

čajno proizvajalci in trgovci večji poudarek namenijo fazi nakupa. Vendar je zelo pomembno, da ne pozabijo na prednakupno fazo in ponakupno fazo. Ravno ti dve fazi sta ključni, da potrošnik pokaže zanimanje za izdelek ali storitev oz. nakup ponovi ter izdelek ali storitve priporoči tudi ostalim. Celostna nakupna izkušnja se navadno začne, ko potrošnik naleti na neko težavo. Ta težava je lahko zelo enostavno rešljiva, kot je npr. potreba po nakupu mleka, ali pa je precej kompleksnejša, kot je potreba pa nakupu hiše. Poleg kompleksnosti se težave lahko razlikujejo tudi glede na konzumacijski namen, npr. ko se mora potrošnik odločiti, ali bo kupil praznično darilo za družinskega člana ali bo ekvivalentno vsoto denarja porabil zase. Potrošniki navedene probleme rešujejo z odločanjem, nanj pa vplivajo različni sprožilci. Odvisno od njih potrošnik razmisli o različnih nakupnih dejavnikih (npr. finančni, sociološki in kulturni, osebni, psihološki) (Shankar 2011).

$V$ vsaki izmed faz celostne nakupne izkušnje potrošniki pridejo v kontakt s točkami stika (angl. touch points) (Baxendale, Macdonald in Wilson 2015), lahko jih imenujemo tudi sprožilne točke (angl. trigger points). Gre za točke, kjer potrošnik pride v neposreden stik z blagovno znamko (npr. družbena omrežja, pogovor s prodajalcem $\mathrm{v}$ prodajalni, oglas v časopisu, akcijske ponudbe, spletne pasice, mnenje družinskih članov ali znancev) v kateri koli fazi celostne nakupne izkušnje. Zelo pomembno je tudi zavedanje, da potrošnik s točkami stika ne pride $\mathrm{v}$ kontakt zgolj v prodajnem okolju, temveč tudi izven njega. Proizvajalci in trgovci morajo razumeti, da se odnos in vedenje potrošnika ob kontaktu s točkami stika lahko bistveno spremenita, tako v pozitivno smer (npr. ob brskanju in sprehajanju po prodajalni se potrošnik spremeni v kupca (Shankar idr. 2011) zaradi akcijske ponudbe nekega izdelka, ki ga prvo- tno ni imel v namenu kupiti) ali pa $\mathrm{v}$ negativno (npr. negativna recenzija izdelka na spletu odvrne potrošnika od nakupa). Dejstvo je, da vseh točk stika proizvajalec ali trgovec ne moreta imeti pod nadzorom. Nadzirata lahko medijske kanale, ki so v njuni lasti (npr. oglaševanje, spletno mesto, programi zvestobe), ter nekatere elemente trženjskega spleta (npr. embalaža, lastnosti izdelka, cena). Nobenega nadzora pa nimata npr. nad razmišljanjem potrošnikov o njihovih potrebah in željah ter preteklih izkušnjah (Lemon in Verhoef 2016). Najpomembnejše točke stika imenujemo »trenutki resnice" (angl. moments of truth), ki jih definiramo kot točke, ki spodbudijo potrošnika, da nadaljuje $z$ nakupnim procesom določenega izdelka ali storitve (Ertemel in Başc1 2015).

Trenutki resnice izhajajo iz tristopenjskega miselnega marketinškega modela (angl. 3-step mental marketing model). Vsi trije koraku so opisani v preglednici 1.

$\mathrm{Z}$ razmahom spletnega nakupovanja in vedno večje uporabe pametnih naprav (Statista b.1.) se je ideja o trenutku resnice razširila v pet različnih trenutkov, ki jih lahko zaznamo znotraj celostne nakupne izkušnje (npr. Lecinski 2009):

- Manj kot trenutek resnice (angl. less than zero moment of truth - $\angle Z M O T)$ : ta faza predstavlja situacijo, ko se je v življenju potencialnega potrošnika nekaj zgodilo, da je postal zainteresiran za določen izdelek ali storitev. Lahko je npr. zaznal plačano objavo na družbenih omrežjih, bil vključen $v$ marketing preko e-mailov ali pa je $\mathrm{z}$ izdelkom stopil v stik preko spletnih oglasov. To se dogaja še preden je potencialni potrošnik zavestno pričel $z$ iskanjem informacij o nekem izdelku ali storitvi oz. opazil potrebo po njih.

- Nični trenutek resnice (angl. zero moment of truth - ZMOT): ta faza se osredotoča na tre- 
nutek, ko potencialni potrošnik začne iskati informacije o izdelku, za katerega je zainteresiran. $\mathrm{V}$ tej fazi bo potencialni potrošnik pregledal spletne recenzije in preučil različne podatke o izdelku, preden se bo premaknil dalje po svoji nakupni poti.

- Prvi trenutek resnice (angl. first moment of truth - FMOT): gre za fazo, ki je osredotočena na trenutek, ko potencialni potrošnik prvič pride $\mathrm{v}$ stik $\mathrm{z}$ izdelkom ali storitvijo. Navadno F MOт traja zgolj nekaj sekund in lahko vključuje potrošnikovo branje opisa izdelka ali njegovo pogovor s prodajnim osebjem, na podlagi katerega potencialni potrošnik bolje razume lastnosti in prednosti izdelka ali storitve ter ugotovi, ali bo $\mathrm{z}$ uporabo lahko zadovoljil svoje potrebe.

- Drugi trenutek resnice (angl. second moment of truth - SMOT): ko potencialni potrošnik prvič pride $\mathrm{v}$ stik $\mathrm{z}$ izdelkom ali storitvijo, se premakne v naslednjo fazo (SMOT). V tej fazi zares izkusi, kaj mu podjetje ponuja. To se lahko zgodi tudi, preden opravi nakup izdelka (npr. ko ima v prodajalni v rokah nov mobilni telefon). Lahko pa se zgodi tudi po opravljanjem nakupu, do česar velikokrat pride, ko potrošnik naroča preko spleta, saj izdelek prvič vidi šele takrat, ko prispe.

- Končni trenutek resnice ali tretji trenutek resnice (angl. ultimate moment of truth/third moment of truth - UMOT): to je faza, ki je osredotočena na povratno informacijo s strani potrošnika. Med to fazo lahko potrošnik deli svoje mnenje direktno s podjetjem ali javno, preko spleta (npr. spletno mesto ali družbena omrežja podjetja), lahko pa svojo povratno informacijo poda ustno, družini ter prijateljem (angl. word of mouth - WOM). Te povratne informacije ostalim potencialnim potrošnikom nakazujejo, kakšne so izkušnje oseb, ki so izdelek ali storitev že uporabile. To pa ima vpliv na to, ali bodo potencialni potrošniki nadaljevali z nakupno potjo ali ne. Zato je ta trenutek imenovan tudi končni, saj bi lahko za potencialne potrošnike predstavljal zмот.

Celostno nakupno izkušnjo lahko prikažemo tudi grafično, temu pravimo mapiranje celostne nakupne izkušnje (angl. customer journey mapping - CJM). To pomeni, da naredimo vizualno deskripcijo poteka dogodkov (korakov nakupne poti), preko katerih naj bi porabniki prišli v stik z blagovno znamko znotraj celostne nakupne izku- šnje. Cilj mapiranja je dodelava procesa na točkah, kjer pride potrošnik v stik z blagovno znamko, z namenom izboljšanja uporabniške izkušnje (angl. customer experience - CX) (Rosenbaum, Losada Otalora in Contreras Ramírez 2017).

Celostna nakupna izkušnja potrošnika se lahko razlikuje glede na vrsto nakupovanja. Shankar (2011) izpostavlja tri vrste nakupovanja - ciljno usmerjeno nakupovanje (angl. goal-directed shopping), nakupovanje, usmerjeno v iskanje raznolikosti (angl. variety-seeking shopping), ter neplanirano oz. impulzivno nakupovanje (angl. unplanned/impulse shopping). Pri ciljno usmerjenem nakupovanju ima potrošnik jasne cilje kaj, kje in kdaj želi nekaj kupiti. Cilji mu pomagajo pri usmerjanju pozornosti proti želenemu izdelku ali storitvi (Donovan idr. 1994). Nekateri cilji na začetku niso konkretni, vendar se oblikujejo sproti, ko se potrošnik premika po različnih stopnjah celostne nakupne izkušnje. Tisti cilji, ki pa so že v začetku konkretni, ga vodijo $\mathrm{v}$ miselni preračun njegove potrošnje (Thaler 1985), vendar so nakupne odločitve včasih sprejete zelo hitro brez preverjanja končnih cen (Dickson in Sawyer 1990). Zato se v veliko primerih zgodi, da se potrošniki ne držijo prvotno določenih finančnih okvirjev (Mahoney 2012). Pri drugi vrsti nakupovanja nakupovanju, usmerjenem $\mathrm{v}$ iskanje raznolikosti - pa je bistveno, da imajo potrošniki na voljo raznoliko izbiro izdelkov ali storitev ter blagovnih znamk. Takšna vrsta potrošnikov ima rada veliko izbiro izdelkov znotraj iste kategorije v sklopu enega nakupa (Simonson 1990). Velike izbire si želijo potrošniki z nizko zvestobo blagovnim znamkam, ki med blagovnimi znamkami zaznavajo zgolj majhne razlike in imajo visoke hedonistične vrednote (Van Trijp, Hoyer in Inman 1996). Odkrivanje novih vizualnih dražljajev (Maimaran in Wheeler 2008) in prostorskih oblik (Levav in Zhu 2009) sta značilna dejavnika za nakupovanje, ki je usmerjeno v raznolikost. Poznamo pa še nenačrtovano oz. impulzivno nakupovanje. Večina potrošnje je nenačrtovane ali impulzivne narave (Inman, Winer in Ferraro 2009), samo $24 \%$ nakupov v prodajalnah je načrtovanih (Mahoney 2012). Impulzivno nakupovanje je zavestna aktivnost, v kateri je nakupna odločitev sprejeta hitro, saj si potrošniki želijo takojšnje gratifikacije. Povzroči lahko konfliktne občutke in nemir. Tisti potrošniki, ki so že po naravi impulzivni, to svojo lastnost kažejo tudi pri nakupovanju (Rook in Fisher 1995).

$V$ prvem valu epidemije covida-19, $v$ prvi polovici leta 2020, pa smo bili priča še eni vrsti nakupovanja- 
paničnemu nakupovanju (Harahap idr. 2021). Le-to je vrsta nakupovanja, za katero je značilno hitro povečanje obsega nakupa, kar običajno povzroči zvišanje cen (npr. povišanje cene mask in razkužil). Takšna vrsta nakupa je pogosto povezana s čustvi pohlepa, ki pa so povezana s strahom (Billore in Anisimova 2021). Panično nakupovanje sprožijo psihološki dejavniki, ki se običajno pojavijo zaradi nepopolnosti ali necelovitosti informacij, ki jih prejme javnost. Zaradi covida-19 se je podobna situacija zgodila tudi pri nas v prvi polovici leta 2020 ter med potrošnike razširila negotovost in zaksrbljenost, ki se je odrazila tudi v načinu njihovega nakupovanja. Začeli so si delati zaloge najnujnejših izdelkov, hrane in pijače (npr. testenine, toaletni papir, omake $z$ dolgim rokom trajanja). Pri potrošnikih se v takšnih pogojih lahko pojavita dve obliki zaskrbljenosti. Prva je, da če danes ne bodo kupili izdelkov, bodo jutri cene višje. Druga pa je, da želenih izdelkov ne bo več na voljo, saj bodo razprodani (Harahap idr. 2021).

Potrošniško vedenje tema raziskovanja že vrsto let. Zaradi vseh novosti, ki se dogajajo v zadnjem obdobju, pa je to področje še dodatno izpostavljeno nenehnim spremembam. Potrošniki so danes vedno zahtevnejšni in bolj izobraženi, zato so tudi njihova pričakovanja višja. Po eni strani si želijo široke izbire, po drugi pa se težko odločajo med velikim številom možnosti. Poleg tega smo danes priča aktivnemu razvoju digitalizacije in uporabe različnih tehnologij ter inovacij. Ta trend se je še dodatno okrepil $v$ zadnjem letu in pol zaradi covida-19, zato so se proizvajalci in trgovci morali hitro prilagoditi na novo situacijo. Posledično se je začela spreminjati tudi celostna nakupna izkušnja. Digitalizacija (npr. spletna trgovina, brezstično plačevanje, spletno svetovanje) in uporaba različnih tehnologij (npr. obogatena resničnost, QR-kode na embalažah, videonakupovanje, "skeniraj plačilo in pojdi« (angl. scan pay \& go), tehnologija beacon) se dopolnjujeta. Zaradi hitrega načina življenja in posledic epidemije covida-19 želijo potrošniki svoj nakup opraviti hitro, enostavno, s čim manj kontakta in higienično. Poleg hitrega prilagajanja na spremembe je za proizvajalce in trgovce zelo pomembno, da uporabljajo in nadgradijo svoj večkanalni pristop (angl. multichannel approach). Pri tem gre za integracijo vseh digitalnih kanalov in fizičnih naprav $\mathrm{v}$ eno optimizirano ter konsistentno celostno nakupno izkušnjo. Kljub vsem prednostim (npr. prilagodljivost, širša dostopnost, enostavnost, hitrost), ki jih prinašata digitalizacija in uporaba tehnologije, je to povezano z visokimi stroški. Poleg tega je potrebno izobraziti zaposlene, saj gre za precej specifična znanja, za katera ni dovolj zgolj osnovna digitalna pismenost. Za optimalne digitalne procese je potrebno tudi analitično znanje za pravilno interpretacijo delovanja spletnih kanalov (npr. spletna trgovina, spletna mesta, družbena omrežja, spletno oglaševanje). Prav tako morajo zaposleni zelo natančno poznati in razumeti delovanje svojih digitalnih kanalov in tehnologije, ki jo uporabljajo, saj le tako lahko nudijo podporo potrošnikom, ko imajo ti vprašanja ali se ne znajdejo. Podjetja pa ne smejo pozabiti tudi na starejše, ki jim prilagajanje na novosti včasih predstavlja izziv.

Menimo, da je najpomembnejše, da se podjetja optimizacije celostne nakupne izkušnje lotijo postopoma. Zavedati se morajo, da gre za dolgoročen proces, $\mathrm{v}$ katerem bodo večkrat naleteli na kakšno oviro. $\mathrm{Na}$ eni strani imajo opravka $s$ potrošniki, ki se neprestano odzivajo na situacijo na trgu in posledično spreminjajo svoje vedenje. Na drugi strani pa so za uspešno implementacijo digitalizacije in uporabe novih tehnologij potrebne visoke investicije ter vlaganja v znanje zaposlenih. Podjetja nimajo lahko naloge, saj se nahajamo $\mathrm{v}$ obdobju, kjer se spremembe dogajajo zelo hitro, zato morajo biti neprestano na preži za novostmi, da so lahko korak pred svojimi konkurenti. Vendar ne glede na vse digitalne in tehnološke priložnosti ne smejo pozabiti na svoje temeljne vrednote, prek njih namreč gradijo najmočnejše odnose s svojimi potrošniki in tako ustvarjajo kvalitetno celostno nakupno izkušnjo.

\section{Literatura}

Applebaum, W. 1951. "Studying Customer Behavior in Retail Stores. « Journal of Marketing 16 (2): 172-178.

Babin, B. J., W. R. Darden in M. Griffin. 1994. »Work and/or Fun: Measuring Hedonic and Utilitarian Shopping Value. " Journal of Consumer Research 20 (4): 644-656.

Bagdare, S., in R. Jain. 2013. "Measuring Retail Customer Experience." International Journal of Retail \& Distribution Management 41 (10): 790-804.

Baxendale, S., E. K. Macdonald in H. N. Wilson. 2015. "The Impact of Different Touchpoints on Brand Consideration. " Journal of Retailing 91 (2): 235-253.

Billore, S., in T. Anisimova. 2021. »Panic Buying Research: A Systematic Literature Review and Future Research Agenda." International Journal of Consumer Studies 45 (4): 777-804.

Briedis, H., A. Kronschnabl, A. Rodriguez in K. Ungerman. 2020. "Adapting to the Next Normal in Retail: The Customer Experience Imperative.« McKinsey \& Company. https://www.mckinsey.com/industries/ 
retail/our-insights/adapting-to-the-next-normal -in-retail-the-customer-experience-imperative.

Dickson, P. R., in A. G. Sawyer. 1990. »The Price Knowledge and Search of Supermarket Shoppers.« Journal of Marketing 54 (3): 42-53.

Donovan, R. J., J. R. Rossiter, G. Marcoolyn in A. Nesdale. 1994. "Store Atmosphere and Purchasing Behavior." Journal of Retailing 70 (3): 283-294.

Ertemel, A. V., in A. Başc1. 2015. »Effects of Zero Moment of Truth on Consumer Buying Decision: An Exploratory Research in Turkey.«International Journal of Social Sciences and Education Research 1 (4): 526-526.

Foster, J., in M. A. McLelland. 2015. »Retail Atmospherics: The Impact of a Brand Dictated Theme." Journal of Retailing and Consumer Services 22 (1): 195205.

Harahap, D. A., K. F. Ferine, N. Irawati in D. Amanah. 2021. "Emerging Advances In E-Commerce? Panic And Impulse Buying During The Covid-19 Pandemic." Systematic Reviews in Pharmacy 12 (3): 224230.

Inman, J. J., R. S. Winer in R. Ferraro. 2009. "The Interplay among Category Characteristics, Customer Characteristics, and Customer Activities on in-Store Decision Making. « Journal of Marketing 73 (5): 19-29.

Lecinski, J. 2009. Winning the Zero Moment of Truth. Google. https://www.thinkwithgoogle.com/_qs/ documents/673/2011-winning-zmot-ebook _research-studies.pdf.

Lemon, K. N., in P. C. Verhoef. 2016. »Understanding Customer Experience Throughout the Customer Journey.« Journal of Marketing 80 (6): 69-96.

Levav, J., in R. (J.) Zhu. 2009. »Seeking Freedom through Variety." Journal of Consumer Research 36 (12): 6oo-610.

Lipowski, Z. J. 1970. »The Conflict of Buridan's Ass or Some Dilemmas of Affluence: The Theory of Attractive Stimulus Overload. «American Journal of Psychiatry 127 (3): 49-55.

Mahoney, S. 2012. "Shopper Engagement: To Touch Is to Buy.«MediaPost Communictations. https://www .mediapost.com/publications/article/174286/ shopper-engagement-to-touch-is-to-buy.html.

Maimaran, M., in C. S. Wheeler. 2008. "Circles, Squares, and Choice: The Effect of Shape Arrays on Uniqueness and Variety Seeking." Journal of Marketing Research 45 (6): 731-740.
Reutskaja, E., in R. M. Hogarth. 2009. "Satisfaction in Choice as a Function of the Number of Alternatives: 'When Goods Satiate.' "Psychology and Marketing 26 (3): 197-203.

Rook, D. W., in R. J. Fisher 1995. »Normative Influences on Impulsive Buying Behavior. "Journal of Consumer Research 22 (3): 305-313.

Rosenbaum, M. S., M. Losada Otalora in G. Contreras Ramírez. 2017. "How to Create a Realistic Customer Journey Map.« Business Horizons 6o (1): 143-150.

Rompay, T. J. van, J. Krooshoop, J. W. M. Verhoeven in A. T. H. Pruyn. 2012. "With or Without You: Interactive Effects of Retail Density and Need for Affiliation on Shopping Pleasure and Spending. « Journal of Business Research 65 (8): 1126-1131.

Schwartz, B. 2004. The Paradox of Choice: Why More Is Less. New York: Ecco.

Sheth, J. 2020. »Impact of Covid-19 on Consumer Behavior: Will the Old Habits Return or Die? « Journal of Business Research 117 (6): 28o-283.

Shankar, V. 2011. Shopper Marketing. Cambridge, MA: Marketing Science Institute.

Shankar, V., J. J. Inman, M. Mantrala, E. Kelley in R. Rizley. 2011. "Innovations in Shopper Marketing: Current Insights and Future Research Issues. « Journal of Retailing 87 (S1): S29-S42.

Simonson, I. 1990. "The Effect of Purchase Quantity and Timing on Variety-Seeking Behavior.« Journal of Marketing Research 27 (2): 150-162.

Stahlberg, M., in V. Maila. 2012. Shopper Marketing: How to Increase Purchase Decisions at the Point of Sale. London: Kogan Page.

Statista. B. 1. »Coronavirus Impact on Retail E-Commerce Website Traffic Worldwide as of June 2020, by Average Monthly Visits (in Billions). «https://www .statista.com/statistics/1112595/covid-19-impact -retail-e-commerce-site-traffic-global.

Thaler, R. 1985. "Mental Accounting and Consumer Choice."Marketing Science 4 (3): 199-214.

"The Evolving Consumer: How Covid-19 Is Changing the Way We Shop." B.l. McKinsey \& Company. https://www.mckinsey.com/about-us/covid-responsecenter/mckinsey-live/webinars/evolving-consumerhow-covid-19-has-changed-us-shopping-habits.

Van Trijp, H., W. Hoyer in J. Inman. 1996. „Why Switch? Product Category: Level Explanations for True VarietySeeking Behavior.« Journal of Marketing Research 33 (3): 281. https://doi.org/10.2307/3152125. 